\section{International Scientific Journal Theoretical \& Applied Science}

p-ISSN: 2308-4944 (print) e-ISSN: 2409-0085 (online)

Year: 2017 Issue: $11 \quad$ Volume: 55

Published: $16.11 .2017 \quad$ http://T-Science.org
Sayyora Yoqubjanovna Batirova the teacher of Namangan state University, Namangan, Uzbekistan

Mahbuba Nurullayevna Abdulleva Doctor of Philosophy, Professor, National University of Uzbekistan, Tashkent, Uzbekistan gulchehra_3@mail.ru

SECTION 30. Philosophy.

\title{
INTER-DISCIPLINARY APPROACH IN THE CONTEXT OF SCIENTIFIC AND SOCIAL DEVELOPMENT
}

\begin{abstract}
Development of modern bio-technologies, nano-sciences, nano-technologies, etc., that the basis of these studies is its information technology, computer modelling whose epistemological basis is an interdisciplinary approach. An interdisciplinary approach in modern society is the driving force for the development of not only scientific but also practical problems.

Key words: cognition, process, approach, inter-disciplinarity, inter-disciplinary approach, synergetics, thinking, system, complexity, sciences, development of science, self-organization.

Language: Russian

Citation: Batirova SY, Abdulleva MN (2017) INTER-DISCIPLINARY APPROACH IN THE CONTEXT OF SCIENTIFIC AND SOCIAL DEVELOPMENT. ISJ Theoretical \& Applied Science, 11 (55): 34-38.

Soi: http://s-o-i.org/1.1/TAS-11-55-6 Doi: crossef https://dx.doi.org/10.15863/TAS.2017.11.55.6

\section{МЕЖДИСЦИПЛИНАРНЫЙ ПОДХОД В КОНТЕКСТЕ НАУЧНОГО И СОЦИАЛЬНОГО РАЗВИТИЕ}

Аннотация: Развитие современных биотехнологий, нанонауки, нанотехнологий и т.д., что основу этих исследований составляет его информаџионная технологии, компьютерное моделирование эпистемологической основой которых является междисциплинарный подход. Междисииплиарный подход в современном обществе является двигатели развития не только научных, но и практических проблем.

Ключевые слова: познание, процесс, подход, междисциплинарность, междисциплинарньй подход, синергетика, мышление, система, сложность, наук, развития науки, самоорганизации.
\end{abstract}

\section{Введение.}

Процесс познание - это неустанный поиск новых методов и подходов познании сложного, многообразного мира. Вектор развития современного познавательного аппарата направлен на познание усложняющегося, взаимосвязанного, взаимообусловленного мира, формированием новых методов методологических установок. Все возрастающая сложности окружающегося мира ставит проблему от чего зависит поведение сложных систем?

Современный познавательный аппарат в соответствии с изучением нелинейных процессов природы пополнился теорией сложных систем (синергетика), которая позволяет исследовать неисследованные стороны нелинейного мира.

Законы, закономерности отражающие процессы линейного мира пополнились новыми научными методами, подходами нелинейного мира. Изучение этого мира не продуктивно в аспекте только дисциплинарного подхода, необходимы подходы, позволяющие изучать сложность.

Познавательный аппарат дополняется междисциплинарным подходы. Как известно, каждая дисциплинарная наука, используя свои познавательные подходы, методы изучает какуюто часть реальности, что находит своё отражение в принципах, гипотезах, теориях, законах конкретной науки. Междисциплинарный подход, формируясь на стыке науки, представляется в виде использования методов одной наук в другой (биофизика, математическая экономика и т.д.), где имеется свой предмет и методы исследования, например, биологические процессы изучается физическими подходами. Другая форма междисциплинарного подхода, использование методов различных наук в изучении одного и того же объекта. 
Современность представила человечеству много проблем, которые надо решать комплексно. Так, например экологические проблемы, проблема человека и т.д.

\section{Основная часть.}

Проблема междисциплинарности - «это пробленарное мышление, «офсетное зрение». Это означает не отказ от дисциплинарного овладения знаниями, но дополнение и насыщение его приемами междисциплинарной подачи материала, формирующими междисциплинарное мышление» [3, с.17-18].

Междисциплинарное мышление основа для формирования познавательного пространства, при решении проблем, общих для интегрирующийся дисциплинарных наук. Изучение этих процессов должно стать основой для формирования определенного типа мышление. Теоретические представление одной науки используются другой дисциплинарной наукой, которые позволяют решать общие проблемы, т.е. речь идет о создании общих методологических, познавательных подходов в междисциплинарных исследованиях.

Длительное время физика и химия обладали междисциплинарным статусом. Позже идеи кибернетики и системного подхода приобрели междисциплинарный статус. В настоящее время, синергетика используя сложный, богатый познавательный арсенал предыдущих исследований, активно трансформирует свои идеи и методы в другие дисциплинарные науки[2, c.12].

Синергетика изучает процесс образования нового, как в живой так и в неживой природе. Необходимыми условиями для этого процесса является: система должна быть в неравновесном состоянии, необходим непрерывный поток материи и энергии сквозь систему, нелинейная связь между элементами системы, характеризующаяся функционированием петли обратной связи. При этих условиях изменение структуры, возникновение новых структур является всеобщей закономерностью как в области живой и неживой природы, так и в ментальной сфере. Так, например, с точки зрения синергетики формирование и функционирование творческого процесса происходит следующим образом: «в мозге происходит своего рода фазовый переход, множество прежде никак не связанных между собой детали неожиданно становятся частицами вполне упорядоченного и преисполненного глубочайшего смысла единства ... речь в данном случае идет о процессах аналогичных тем, что уже известны нам из других областей синергетики. В результате той или иной флуктуации («озарения» или вспышки) возникает новый параметр порядка (новая идея) благодаря которой нам и удаётся найти взаимосвязь между отдельными деталями и упорядочить их, подчинив себе. Однако все это происходит благодаря самоорганизации самоорганизации наших мыслей в данном случае» [8, с.232].

Синергетика, как междисциплинарный подход, как методология неклассической науки, основывается на философских идеях и положениях формирует регулятивные принципы, методы и формы познания, которые применяются при изучении окружающею гас мира. Изучая природные закономерности классическая наука пренебрегала хаотическими проявлениями: турбулентностью, колебаниями численности популяций растений и животных, опериодичностью сокращений сердечных мышц т.д. Объектом исследований классической науки рассматривались в аспекте устойчивости и регулярности и все что не укладывалось в рамки классической модели познания оставлялось вне научных исследований считалось субъективной ошибкой исследователя. Человечество в начале $\mathrm{XX}$ века толкнулось с проблемой сложности. На этом этапе развития наука разрабатывал научный аппарат познавательного процесса, основанного на детерминистской основе, редукции, принципе суперпозиции, когда сумма частей равна целому. Вторая половина ХX века характеризуется формированием теории хаоса или нелинейной науки. Развитие науки, новейших технологий, методологии, познавательного аппарата в значительной степени определяется успехами той или иной науки.

На этом этапе развития науки пришло понимание того, что такие понятия как: вероятность, случайность, неопределенность и т.д. являются существенными, объективными характеристиками мира. Современная наука доказала их онтологическую сущность.

Человечество всегда интересовали проблемы сложности. Так, например, Лейбниц высказал мысль. Что клетки, растения, ягоды представляют собой более или менее сложные автомашины. Он создал теорию сложных систем, основываясь на понятиях, принципах классической механики, на возможностях детерминация, редукционизма и т.д.

Как уже отмечалось сложные явления нельзя познать методами отдельно взятых наук, при соблюдении определенных условий формируется междисциплинарных подход. И важную роль в формировании междисциплинарного подхода играет философия. Она играет регулятивную роль не только в формировании мировоззрения человека, но и в выборе познавательной методологии, как регулятива познавательного процесса. Методология, основываясь на философских принципах, идеях и положениях формирует регулятивные принципы, методы и 
формы познания. Исследователь должен выбрать необходимую методологию для изучения окружающего мира. "В современных работах по методологии научного познания справедливо отмечается, что философская методология, основываясь на общефилософских принципах и законах, исторически возникала и развивается на основе гносеологии, эпистемологии и логики" [6, c.16].

История развития науки свидетельствует, о том что методологиях. Методология, основанная на иных познавательных принципах т.е. то, что не адекватно установившейся методологии не принимается научным сообществом. Примером являются исследования А.Пуанкаре по нелинейным процессам.

Формирование междисциплинарного подхода это не только интеграция наук. Как отмечает В.Буданов “синергетика находится в диалоге и пытается ассоциировать другие современные сценарии, такие как философия становления, эволюционная эпистемология, когнитивистика, рефлексивное управление, теория искусственного интеллекта, интегральное психология, медицина и т.д. То синергетический мегапроект далек от завершения, скорее он входит в фазу конструктивной зрелости ... Именно на этой стадии синергетика и философия как никогда нуждаются друг в друге" [1, с.155].

Междисциплинарное взаимодействие дисциплинарных наук и философии формирует ряд методологических подходов и программ на стыке формирующихся дисциплин. Это способствует расширению возможностей развития эпистемологии, открывая новые перспективы. Но вместе возможен и другой путь, как отличает И.Т.Касавин "феномен междисциплинарности являет собой один из современных вызовов эпистемологии, как ее очередным кризисом, так и новым взлетом". "Междисциплинарность часто употребляется также как синтез теоретического знания и технологий, знания и умений, причем и те и другие построены на определенных когнитивных стратегиях, т.е. эпистемологический контекст междисциплинарных исследований является неотъемлемой их компонентой” [4].

Эпистемологический подход определяет познание сложных явлений, поскольку выявление новых сторон требует новых подходов, новых методологических установок, которые должны адекватно отражать изучаемые явления.

Значимость междисциплинарного подхода определяется не только развитием современный науки, но и использованием данного подхода в решении социальных проблем. “Современное общество, которое не может существовать без нововведений, должно их стимулировать, а государственная инновационная политика - ориентироваться на поддержку конкретных проектов, учитывая не только гуманистическую экспертизу, по но и междисциплинарные стратегии" [9, с.39].

Основу такого отношения составляет современная эпистемологическая установка “знание - объект”, где познавательный процесс отличается от прежнего субъект - объективного отношения. В новом подходе функции познающего субъекта дают возможность расширять сферу исследования объекта. Познающий владеет определенным знанием и это знание позволяет ему выбирать методологию исследования.

Современное развитие наук, основываясь на междисциплинарных исследованиях, достигает успехов как в научной так и практической деятельности. Развитие современных биотехнологии, нанотехнологий и т.д. результат применения междисциплинарных подходов (как синтез теоретического знания и технологий, знания и умения) в исследовании сложных объектов.

Ocобое место в развитии научных исследований занимают информационные технологии, компьютерные модели и эксперименты, дающие виртуальную возможность познакомится с возможными сценариями развития изучаемого объекта. Возможности и условия проведения компьютерного моделирования, как известно, отличаются от других видов моделирования. Они используются при исследовании очень сложных проблем современной науки, результаты которых используются в практической деятельности человека.

Компьютерная моделирование даст возможность проводит научной анализ и обсуждать области, которые находятся на стыке нескольких дисциплин. Многие отрасли современной науки при решении сложных проблем обращаются к компьютерному моделированию. Так, например, как исследовать такую сложную систему как “разум - мозг”. Для исследования сложной системы “разум - мозг”, нужна междисциплинарная программа по компьютерной нейробиологии, физике, инженерии, молекулярной биологии, медицине и эпистемологии[5, с.305].

В XX веке компьютерные информационные технологии мошнейший фундамент для развития естественных наук. Информационные технологии, - это система взаимосвязанных научных, технологических, инженерных дисциплин, изучающих методы эффективной организации труда людей. В их задачу входит при лпределенных методах и способа сбора, накопления, хранение, поиске, обработки, передачи и выдачи информации. 
Развитие страны требует колоссальных интеллектуальных усилий ученый, способных генерировать новые идеи, инновации и материальное стимулирование. Внедрение инноваций один из важнейших путей развития страна.

Сегодня термин инновация носит междисциплинарный характер, который используется во многих отраслях науки экономики, научно-технической сфер, социологии, философии, педагогике, образования[7].

Развитие современных биотехнологий, нанонауки, нанотехнологий и т.д., что основу этих исследований составляет его информационная технологии, компьтерное моделирование эпистемологической основой которых является междисциплинарный подход. В логико-гносеологическое плане представляется, что абстракций высокого уровня отраженные в информационных технологиях реализуются в каждом конкретном случае со своей спецификой. Она как процесс используют совокупность средства и метода сбора, обработки и передачи данных, используется для получения информации нового качества изучаемого информационный объект.

Междисциплинарный подход в современном обществе явлется двигатели развития не только научных, но и практических проблем. Междисциплинарный подход

Так, например, синергетический подход, в столь разных по природе живой и неживой природе позволил установить нечто общее между ними.

Междисциплинарность содружество различных наук, стремящихся решить свои проблемы совместно, но при этом отдавая приоритет конкретной дисциплинарной науке. Так, например Э.Морен отличает, что «междисциплинарность может означать только и просто то, что различные дисциплины встречаются за общим столом, подобно тому как разные нации собираются в ООН исключительно для того чтобы заявить о своих собственных национальных правах и своем суверенитете по отношению к посягательствам соседа. Но междисциплинарность может стремится также к обмену и кооперации, в результате чего междисциплинарность может становится чем-то органическим» [10, с.457].

\section{Заключение.}

Таким образом одним из локомотивов развития современной науки является междисциплинарный подход, который имеет возможность, как для углубленного так и для расширения научных исследований так и для экстрополяции выводов, научное прогнозирования событий.

Концепция самоорганизации, возникла как междисциплинарный подход, показывает что в мире все взаимосвязаны, взаимообусловлены.

Основу синергетического подхода составляет системной подход. «Синергетика опирается на очень разные дисциплины, среди которых не только физика, химия и биология, но и также социология и экономика, можно поэтому ожидать, что открытые и описанные синергетикой закономерности уже так или иначе будут представлены в различных областях науки, и у нас появится возможность увидеть возникновение в свете синергетики новой, единой картины мира, составленной, подобно мозаике, из множества отдельных, собранных наукой фактов»[8, с.25].

\section{References:}

1. Budanov V. (2006) Methodology and principles of the Synergetics // Basics of Philosophy, 2006. No.1(3), p.155.

2. Kiyashenko L. (2006) Phenomenon transdisciplinarity - experience of philosophical analysis // Filosofija, Santabka. 2006. vol. 14. No. 2. ISSN 1822-430x print/1822-4318 online, p. 12.

3. Knigin A.N. (2008) Interdisciplinarity: the main issue // Tomsk State University, 2008. No.3(4), p.17-18.
4. Knyazeva E.N. (2017) Transdisciplinary research strategy. Available: http://IPHras.ru (Accessed: 10.11.2017).

5. Maynser K. (2008) Slozhnosistemnoe thinking. Fabric. Mind. Humanity. New sintez-7. -M., 2008. p.305.

6. (2010) Methodological issues of disciplinary and interdisciplinary research in the social and humanitarian Sciences. -St. Peterburg, 2010. -p. 16.

7. Soshenko V.I. (2013) Interdisciplinary concept of innovation // Vestnik TSPU, 2013. 13 (141). p. $136-144$ 


\begin{tabular}{l|lrl|l|ll} 
& ISRA (India) & $=\mathbf{1 . 3 4 4}$ & SIS (USA) & $=\mathbf{0 . 9 1 2}$ & ICV (Poland) & $=\mathbf{6 . 6 3 0}$ \\
Impact Factor: & ISI (Dubai, UAE) $=\mathbf{0 . 8 2 9}$ & PUHL (Russia) $=\mathbf{0 . 2 0 7}$ & PIF (India) & $=\mathbf{1 . 9 4 0}$ \\
& GIF (Australia) & $\mathbf{0 . 5 6 4}$ & ESJI (KZ) & $=3.860$ & IBI (India) & $=\mathbf{4 . 2 6 0}$ \\
& JIF & $\mathbf{1 . 5 0 0}$ & SJIF (Morocco) & $=\mathbf{2 . 0 3 1}$ & & \\
\hline
\end{tabular}

8. Haken G. (2003) Synergetics: teaching about interaction. -Moscow-Izhevsk, 2003. -p. 232.

9. Shostka V.I. (2017) Methodology of modern science and the problem of forming an interdisciplinary approach Questions of spiritual culture of the philosophical Sciences, p. 39.

10. Morin E. (2005) Method. Nature. Nature. -M.: Progress-traditions, 2005. -457. 